\title{
Association between serum bilirubin and migraine in children and adolescents
}

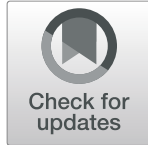

Hosna S. Elshony*, Wafik M. El Sheikh and Mostafa S. Melake

\begin{abstract}
Background: Migraine in children and adolescents is very common and can be associated with equivalents, psychiatric disorders, or abnormal electroencephalogram findings. Neurogenic inflammation is involved in migraine pathogenesis where pro-inflammatory cytokines play a significant role. Recent studies have demonstrated that serum bilirubin can be considered as an antioxidant and cytoprotective agent and that its concentration may be influenced in migraine by neurogenic inflammation. Various studies have observed reduced serum bilirubin in migrainous adults, and few studies investigated the association between serum bilirubin and migraine in children and adolescents.

Objectives: To study the association between serum bilirubin and migraine in children and adolescents.

Patients and method: Serum samples were collected from 40 migrainous children and adolescents and from 40 controls. Total, direct, and indirect bilirubin concentrations were measured. Headache features, migraine equivalents, psychiatric comorbidity, and electroencephalogram findings were documented in migraineurs.

Results: Serum total, direct, and indirect bilirubin concentrations were significantly lower in migraineurs than controls. This was statistically significant associated with abnormal electroencephalogram findings during headachefree periods and not statistically significant associated with any headache feature, abnormal electroencephalogram findings during headache attacks, or psychiatric comorbidity.

Conclusion: Serum bilirubin concentration is lower in migrainous children and adolescents compared to control, with no association with specific migraine type or features, and thus may be considered a useful marker for neurogenic inflammation in migraine.
\end{abstract}

Keywords: Migraine, Serum bilirubin, Migrainous children and adolescents

\section{Introduction}

Migraine is one of the most common causes of primary headaches in childhood [1]. Its prevalence increases throughout childhood, affecting 1-3\% of 3- to 7-year-olds, $4-11 \%$ of 7 - to 11 -year-olds, and 8-28\% of teenagers (13-18 years old) [2]. It may be associated with migraine equivalents which are common clinical conditions, often occurring without a headache component, as repeated episodes with complete remission between episodes [3]. Migraine may be also associated with comorbid psychiatric or behavioral disorders $[4,5]$.

\footnotetext{
*Correspondence: hosna.saad28@gmail.com

Department of Neuropsychiatry, Faculty of Medicine, Menoufia University, Menoufia, Egypt
}

\section{Springer Open}

(c) The Author(s). 2020 Open Access This article is licensed under a Creative Commons Attribution 4.0 International License, which permits use, sharing, adaptation, distribution and reproduction in any medium or format, as long as you give appropriate credit to the original author(s) and the source, provide a link to the Creative Commons licence, and indicate if changes were made. The images or other third party material in this article are included in the article's Creative Commons licence, unless indicated otherwise in a credit line to the material. If material is not included in the article's Creative Commons licence and your intended use is not permitted by statutory regulation or exceeds the permitted use, you will need to obtain permission directly from the copyright holder. To view a copy of this licence, visit http://creativecommons.org/licenses/by/4.0/.

Electroencephalography (EEG) studies in children and adolescents with migraine have shown some abnormalities. Some authors in the last years reported these EEG abnormalities with frequency varying from $11 \%$ in some studies to $74 \%$ in others [6].

Important studies have been made for understanding the pathophysiology of migraine [7] and have shown that inflammation plays a significant role in the pathogenesis of migraine where largely pro-inflammatory cytokines are released and involved in the sensitization of nerve endings during migraine headache attack [8].

Bilirubin has been seen as a toxic waste product since it is a product of heme metabolism. However, recent studies have demonstrated that it possesses cytoprotective and 
strong antioxidant properties. Lower serum bilirubin concentration in migraine may be a primary finding and risk factor or may be a secondary phenomenon caused by the existence of neurogenic inflammation and high oxidative stress during migraine [9].

All previous studies done on bilirubin were made on adult or old age patients. Therefore, in our current study, we analyzed serum bilirubin as an inflammatory marker in migrainous children and adolescents, and investigated the possible relationship between serum bilirubin and different headache features, the presence or absence of migraine equivalents, the presence or absence of psychiatric comorbidity, and electroencephalogram (EEG) findings in this age group.

The abstract of this manuscript was presented in the World Congress of Neurology (WCN) 19 [10].

\section{Patients and methods}

A total of 40 children and adolescents diagnosed with migraine were recruited to this study. All patients had been diagnosed with migraine according to the International Headache Society criteria, third edition, beta version (ICHD, 3rd edition, beta version) [11]. They were collected from the pediatric clinic and our neuropsychiatric clinic of Menoufia University Hospital in the period from March 2016 to August 2017. Both sexes were included in the study with age ranging from 6 to 18 years old. We excluded patients who had known chronic liver diseases, kidney diseases, infectious diseases, malignant tumor, metabolic syndrome, cardiac or cerebrovascular diseases, hypertension, diabetes, fever or abnormal erythrocyte sedimentation rate (ESR), and a current or past personal history of epilepsy.

Over the same period, 40 sex- and age-matched children and adolescents selected from patients' relatives, from other patients visiting the Menoufia University Hospital with different diagnosis, and from general population were recruited in the study as controls with no present or past history of migraine. So, we had two groups: the migraine group and the control group.

All participants were subjected to general examination including measurement of pulse, blood pressure, and temperature; chest, cardiovascular, and gastrointestinal examination; and complete neurological examination using neurology sheet by the same neurology staff.

Fasting blood samples were collected from all participants. Serum total bilirubin (Tbil), direct bilirubin (Dbil), indirect bilirubin (Ibil), alanine aminotransferase (ALT), and aspartate aminotransferase (AST) were determined by enzymatic method. Erythrocyte sedimentation rate (ESR) was determined using the Westergren method. Individuals with abnormal ALT, AST, or ESR concentrations were also excluded from this study.
The patients in the migraine group were further subjected to the following:

(1) An interview about the history of headache using headache sheet (including character, duration, intensity, frequency, site, radiation, aura, association of headache, postdrome, precipitating factors, relieving factors, the previous treatment and efficacy, and family history of headache).

(2) Migraine equivalents' investigation performed by an interview during the initial assessment of the migraine group and the diagnosis was based on the presence of the typical clinical features of the migraine equivalents included in the International Classification of Headache Disorders diagnostic criteria, 3rd edition beta version. Possible organic causes of the symptoms: for example, other neurological diseases for benign paroxysmal vertigo or gastroenterological abnormalities for abdominal migraine and cyclical vomiting were investigated and their occurrence leads to patient exclusion. Both patients who had complained of migraine equivalents only in the past and those who continued to suffer from one or more migraine equivalents were included.

(3) The following classifications: (a) classifying the type of migraine into chronic and episodic migraine, and into migraine with aura (including its type) and without aura; (b) classifying the frequency of headache episodes as high (from weekly to daily episodes) and low (from less than once a month to three episodes per month)-the cut point was chosen to distinguish patients who need prophylactic treatment from those who do not [12, 13]; and (c) classifying pain rating on a graduate scale at three levels of severity-mild pain, allowing the patient to continue his/her daily activities; moderate pain, leading to interruption of patient activities; and severe pain, forcing the child to go to bed [12].

(4) Psychiatric assessment for the major Axis I psychiatric disorders (all mental disorders except personality disorders and mental retardation) using Mini International Neuropsychiatric Interview for Children (MINI-KID) [14]. Both patients and controls were drug naive. Psychological evaluation was performed in a single session by the same examiner. In order to exclude a possible direct effect of pain on psychological assessment, we ensured that no one of the participants had a headache attack within $24 \mathrm{~h}$ before the psychological study.

(5) Electroencephalogram (EEG), performed twice: one of EEG recordings was done during a headache 
attack (most of the patients were in an attack at the time of initial assessment), and the other one during headache-free period (interictal). EEG evaluations were done at the Electroencephalogram Laboratory of the Department of Neuropsychiatry, Menoufia University Hospital, using a Nihon Koden EEG 9200 K, VER 05-70, made in Japan. Electrodes were positioned according to the international 1020 system. The total recording time for each electroencephalogram was 20 min. During electroencephalogram recordings, hyperventilation was performed for $3 \mathrm{~min}$; intermittent photic stimulations were administered at 2, 5, 6, 8, 10, 13, 16, 18, and $21 \mathrm{~Hz}$ frequencies (10 s flash, alternating with $10 \mathrm{~s}$ of rest); and patients were asked to open and close their eyes. To avoid drowsiness, patients were periodically alerted and told to open their eyes. Slow waves, sharp waves, and spikes were considered electroencephalogram abnormalities.

\section{Statistical analysis}

The data were shown as means $\pm \mathrm{SD}$. We recruited individuals matching with age and gender of patients with migraine to avoid the effects from gender and age on the serum bilirubin concentration. Chi-square test is a test of significance used for comparison between two groups having qualitative variables. $F$ test (ANOVA-analysis of variance) is a test of significance used for comparison between more than two groups having variables. $t$ test is a test of significance used for comparison between two groups having quantitative variables with different variance (parametric test). The data were collected, tabulated, and statistically analyzed using SPSS (Statistical Package for Social Science) program, version 21 (IBM Corp; Released 2012; IBM SPSS Statistics for Windows, Version 21.0. Armonk, NY: IBM Corp). $p<0.05$ was determined as statistically significant, whereas $p$ value $>$ 0.001 was considered to be highly statistically significant; on the other hand, $p$ value $<0.05$ was considered statistically not significant.

\section{Results}

The clinical and laboratory parameters of all patients and controls are presented in Table 1. The migraine group included 40 patients: 16 patients (40\%) were males and 24 patients $(60 \%)$ were females. Their age ranged from 7 to 17 years with mean age $12.50 \pm 2.621$ years. The control group included 40 patients. They were 14 (35\%) males and 26 (65\%) females. Their age ranged from 7 to 17 years with mean age $12.08 \pm 2.693$ years. BMI for patients was $18.23 \pm 2.02$ and control $17.87 \pm$ 2.16 with no significant difference between both groups.

In the migraine group, the average serum concentration of Tbil, Dbil, and Ibil was $0.522 \mathrm{mg} / \mathrm{dl}, 0.177 \mathrm{mg} / \mathrm{dl}$, and $0.345 \mathrm{mg} / \mathrm{dl}$, respectively. This average was highly significantly lower in patients with migraine than controls, as shown in Table 1 and Fig. 1 with no significant difference regarding AST and ALT levels between both groups.

On correlating this lower level of serum bilirubin concentration (Tbil, Dbil, and Ibil) within the migraine group, all the 40 patients had episodic migraine. There was no statistically significant association between serum bilirubin concentration (Tbil, Dbil, and Ibil) and any headache feature (the presence or absence of aura and its type, the presence or absence of migraine equivalents, the frequency of attacks or pain severity rating), as shown in Table 2. There was a statistically significant difference between migrainous patients with psychiatric comorbidity and those with no psychiatric comorbidity as regards Ibil concentration only, while there was no statistically significant difference between them as

Table 1 Demographics and laboratory data of the migraine and control groups

\begin{tabular}{|c|c|c|c|c|}
\hline Variables & Migraine group, $\boldsymbol{N}=40$ & Control group, $\boldsymbol{N}=40$ & Test of significance & $\boldsymbol{p}$ value \\
\hline \multicolumn{5}{|l|}{ Gender } \\
\hline Male & $16(40.0 \%)$ & $14(35.0 \%)$ & ${ }^{*} 0.213$ & 0.644 \\
\hline Female & $24(60.0 \% 0)$ & $26(65.0 \%)$ & & \\
\hline Age in years & $12.50 \pm 2.621$ & $12.08 \pm 2.693$ & $* * 0.715$ & 0.477 \\
\hline Total bilirubin $(0.2-1.2 \mathrm{mg} / \mathrm{dl})$, mean $\pm S D$ & $0.522 \pm .1395$ & $0.835 \pm .1475$ & $* * 9.767$ & 0.000 \\
\hline Direct bilirubin $(0.1-0.4 \mathrm{mg} / \mathrm{dl})$, mean $\pm S D$ & $0.177 \pm .0494$ & $0.244 \pm .0494$ & **6.064 & 0.000 \\
\hline Indirect bilirubin $(\mathbf{0} .1-\mathbf{0 . 8} \mathbf{m g} / \mathrm{dl})$, Mean $\pm S D$ & $0.345 \pm .0910$ & $0.596 \pm .1128$ & **10.928 & 0.000 \\
\hline ALT & $13.955 \pm 2.4633$ & $16.740 \pm 2.1140$ & **5.426 & .000 \\
\hline AST & $16.500 \pm 2.1031$ & $18.063 \pm 2.3457$ & **3.137 & .002 \\
\hline BMI & $18.23 \pm 2.02$ & $17.87 \pm 2.16$ & ${ }^{* *} 0.773$ & 0.442 \\
\hline
\end{tabular}




\section{Total, Direct and Indirect bilirubin}

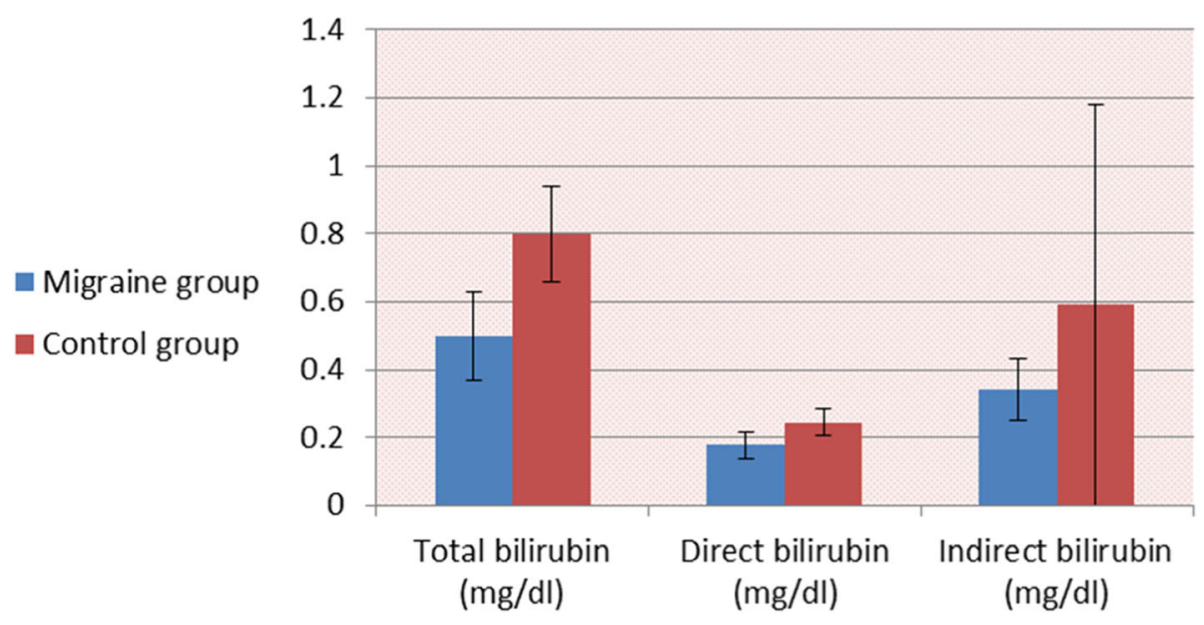

Fig. 1 Lower serum total, direct, and indirect bilirubin concentrations in the migraine group compared with the control group

regards Tbil and Dbil concentrations, as shown in Table 3. On applying multiple linear regression analysis between age, gender, liver functions, and total bilirubin in cases of migraine, for increased total bilirubin (Tab), it was found that sex and AST were significant predictors for total bilirubin and male gender is a protective factor than female (odds $=0.423$ ) while increased AST is more risky to increase total bilirubin by 1.12 -folds. Other variables (age and ALT) were non-significant predictors
(Table 4). As for BMI, there was an inverse correlation with serum bilirubin; the more the BMI, the less the serum bilirubin (Table 4). During headache attacks, there was no statistically significant difference between migrainous patients with normal EEG findings and those with abnormal EEG findings as regards serum bilirubin concentration (Tbil, Dbil, and Ibil). On the other hand, during headache-free periods, migrainous patients with abnormal EEG findings had statistically significant lower

Table 2 The relationship between level of serum bilirubin and migraine headache features

\begin{tabular}{|c|c|c|c|}
\hline & Total bilirubin, mean \pm SD & Direct bilirubin, mean \pm SD & Indirect bilirubin, mean \pm SD \\
\hline \multicolumn{4}{|l|}{ Aura } \\
\hline Without & $0.51 \pm 0.14$ & $0.17 \pm 0.04$ & $0.34 \pm 0.09$ \\
\hline Visual aura & $0.55 \pm 0.14$ & $0.18 \pm 0.05$ & $0.36 \pm 0.09$ \\
\hline Auditory aura & $0.49 \pm 0.16$ & $0.18 \pm 0.07$ & $0.31 \pm 0.09$ \\
\hline$p$ value, ${ }^{*}$ ANOVA test & 0.764 & 0.732 & 0.738 \\
\hline \multicolumn{4}{|l|}{ Migraine equivalents } \\
\hline Absent & $0.52 \pm 0.13$ & $0.17 \pm 0.04$ & $0.34 \pm 0.09$ \\
\hline Present & $0.49 \pm 0.14$ & $0.16 \pm 0.05$ & $0.32 \pm 0.09$ \\
\hline$p$ value, ${ }^{* *} t$ test & 0.552 & 0.666 & 0.498 \\
\hline \multicolumn{4}{|l|}{ Frequency of episodes } \\
\hline High & $0.54 \pm 0.13$ & $0.18 \pm 0.04$ & $0.36 \pm 0.09$ \\
\hline Low & $0.49 \pm 0.14$ & $0.17 \pm 0.05$ & $0.32 \pm 0.09$ \\
\hline$p$ value, ${ }^{* *} t$ test & 0.278 & 0.459 & 0.207 \\
\hline \multicolumn{4}{|l|}{ Pain rating } \\
\hline Mild & $0.49 \pm 0.12$ & $0.17 \pm 0.04$ & $0.32 \pm 0.07$ \\
\hline Moderate & $0.50 \pm 0.09$ & $0.16 \pm 0.03$ & $0.34 \pm 0.06$ \\
\hline Severe & $0.53 \pm 0.16$ & $0.18 \pm 0.05$ & $0.35 \pm 0.10$ \\
\hline$p$ value, ${ }^{*}$ ANOVA test & 0.691 & 0.749 & 0.616 \\
\hline
\end{tabular}

* Anova test ${ }^{*}$ t test 
Table 3 The relationship between serum bilirubin concentration and psychiatric comorbidity

\begin{tabular}{llll}
\hline MINI-KID & Total bilirubin, mean \pm SD & Direct bilirubin, mean \pm SD & Indirect bilirubin, mean \pm SD \\
\hline Free & $0.715 \pm 0.21$ & $0.21 \pm 0.05$ & $0.50 \pm 0.16$ \\
Comorbid psychiatric disorders & $0.63 \pm 0.21$ & $0.21 \pm 0.06$ & $0.43 \pm 0.15$ \\
$\boldsymbol{t}$ test & 1.67 & 0.33 & 2.05 \\
$\boldsymbol{p}$ value & 0.09 & 0.73 & 0.04 \\
\hline
\end{tabular}

levels of serum bilirubin concentration (Tbil, Dbil, and Ibil) than those with normal EEG findings, as shown in Table 5.

\section{Discussion}

Migraine headache is very common in childhood [1]. It may be associated with migraine equivalents which are common clinical conditions, often occurring without a headache component, as repeated episodes with complete remission between episodes [3]. They include abdominal migraine, cyclical vomiting, benign paroxysmal vertigo, and benign paroxysmal torticollis [15]. There is also growing evidence showing increased comorbidity between migraine and several psychiatric conditions $[4,5]$ and abnormal electroencephalography (EEG) findings [6].

Inflammation has an important role in the process of migraine, and recently, studies showed that bilirubin has cytoprotective and antioxidant properties and that existence of neurogenic inflammation and high oxidative stress during migraine is associated with lower serum bilirubin concentration [9].

The purpose of our study was to assess the clinical association between serum bilirubin and migraine syndrome in children and adolescents.

This study was carried out on 40 children and adolescents suffering from migraine, diagnosed according to the ICHD, 3rd edition, beta version. They were compared to 40 controls of children and adolescents not suffering from migraine.

In our study, the main finding was that serum level of bilirubin was significantly lower in children and adolescent patients with migraine compared with healthy controls. Before 2015, there was no published study that had investigated the association between serum bilirubin and

Table 4 Multiple linear regression analysis between age, gender, liver functions, and total bilirubin in cases of migraine

\begin{tabular}{llll}
\hline $\begin{array}{l}\text { Independent } \\
\text { variables }\end{array}$ & \multicolumn{3}{l}{ Total bilirubin (dependent variable) } \\
\cline { 2 - 4 } & Odds & Significance & $95 \%$ Cl (lower-upper) \\
\hline Age & 0.244 & 0.113 & $-0.003-0.029$ \\
Sex (male) & 0.423 & 0.008 & $0.033-0.205$ \\
ALT & -0.023 & 0.363 & $-0.042-0.016$ \\
AST & 1.12 & $>0.001$ & $0.041-0.108$ \\
BMI & -0.066 & 0.558 & $-0.03-0.016$ \\
\hline
\end{tabular}

migraine. Our results agree with the results done by Peng and colleagues [16] and Cao and colleagues [17] who reported in their studies that Tbil, Dbil, and Ibil concentrations were significantly lower in patients with migraine than healthy controls. Possible explanation of lower serum bilirubin in migraine may be as follows: Inflammation plays a central role in the pathogenesis and etiology of migraine with emerging evidence that several cytokines such as interleukin-6 (IL-6), tumor necrosis factor (TNF), and interleukin-10 (IL-10) are implicated in the pathogenesis of migraine causing sensitization of nerve endings during headache attacks $[18,19]$. Interestingly, a negative correlation between direct bilirubin and C-reactive protein (CRP), as a marker that is increased in inflammation, was well established in adult and old migraine patients. These findings, combined with our results, point in an indirect way to the possibility that serum bilirubin may provide a protection against inflammation irrespective to the studied age group [20]. But, whether lower bilirubin level in migraine results from an overconsumption of bilirubin by neurogenic inflammation or a primary deficit and not a physiological phenomenon associated with consumption by inflammation has not yet been established. Thus, future studies and investigations are still required about the exact mechanism.

Till now, there are no studies that disagree with our results as regards lower serum bilirubin in migraine.

On correlating serum bilirubin levels within the migraine group with different headache features and migraine associations, there was no statistically significant association between serum bilirubin concentration (Tbil, Dbil, and Ibil) and any headache feature or the presence or absence of migraine equivalents or abnormal EEG findings during headache attacks. On the other hand, during headache-free periods, migrainous patients with abnormal EEG findings had statistically significant lower levels of serum bilirubin concentration (Tbil, Dbil, and Ibil) than those with normal EEG findings. This may be explained by the fact that in the absence of headache (headache-free periods), migrainous patients with abnormal EEG findings have more lower bilirubin level than those with normal EEG; thus, more lower level of bilirubin reflects much more consumption by inflammation or being much more susceptible to neurogenic inflammation or the presence of subclinical electrical activity 
Table 5 The relationship between serum bilirubin concentration results and EEG findings during both headache attacks and during headache-free periods (at least 2 days after the most recent attack)

\begin{tabular}{|c|c|c|c|}
\hline EEG findings & $\begin{array}{l}\text { Total bilirubin, } \\
\text { mean } \pm S D\end{array}$ & $\begin{array}{l}\text { Direct bilirubin, } \\
\text { mean } \pm \text { SD }\end{array}$ & $\begin{array}{l}\text { Indirect bilirubin, } \\
\text { mean } \pm \mathrm{SD}\end{array}$ \\
\hline \multicolumn{4}{|c|}{ During headache attacks } \\
\hline $\begin{array}{l}\text { Normal } \\
(26)\end{array}$ & $0.53 \pm 0.13$ & $0.18 \pm 0.04$ & $0.35 \pm 0.08$ \\
\hline $\begin{array}{l}\text { Abnormal } \\
\text { (14) }\end{array}$ & $0.49 \pm 0.14$ & $0.16 \pm 0.05$ & $0.32 \pm 0.09$ \\
\hline $\begin{array}{l}p \text { value, }{ }^{* * t} t \\
\text { test }\end{array}$ & 0.319 & 0.317 & 0.326 \\
\hline \multicolumn{4}{|c|}{ During headache-free periods } \\
\hline $\begin{array}{l}\text { Normal } \\
\text { (35) }\end{array}$ & $0.69 \pm 0.20$ & $0.21 \pm 0.05$ & $0.48 \pm 0.16$ \\
\hline $\begin{array}{l}\text { Abnormal } \\
\text { (5) }\end{array}$ & $0.44 \pm 0.16$ & $0.14 \pm 0.05$ & $0.29 \pm 0.10$ \\
\hline $\begin{array}{l}p \text { value, }{ }^{* *} t \\
\text { test }\end{array}$ & 0.010 & 0.018 & 0.012 \\
\hline
\end{tabular}

and that can be detected by EEG even in the absence of headache attack. But, this lower level does not affect the clinical expression of migraine or its associations. No previous studies had investigated this issue, so this observation requires much more investigations and larger studies to be ascertained.

For psychiatric comorbidity, there was statistically significant difference between migrainous patients with psychiatric comorbidity and those with no psychiatric comorbidity as regards serum indirect bilirubin concentration only, while there was no statistically significant difference between them as regards serum total or direct bilirubin concentration. In fact, no previous studies had investigated the association between serum bilirubin level and primary psychiatric disorders in general or psychiatric disorders comorbid with migraine. So, larger studies with larger sample size are needed to investigate this relationship before trying to find an explanation.

In our study, we had several limitations. A relatively small sample size was a major limitation. We did not compare levels of serum bilirubin between migraine patients on anti-inflammatory treatment and those with no anti-inflammatory treatment. Larger cross-sectional and prospective studies are needed to detect the possible mechanism of lower bilirubin levels in patients with migraine and to establish whether this may be used as a useful biomarker for neurogenic inflammation in patients with migraine guiding diagnosis and therapy. Studies are also required to correlate biomarkers of inflammation in migraine and the clinical expression of migraine features, its associations, psychiatric comorbidity, and EEG findings.

\section{Conclusion}

Lower serum bilirubin concentration may be used as a useful biomarker of neurogenic inflammation in migraine patients irrespective of age, migraine features, or association.

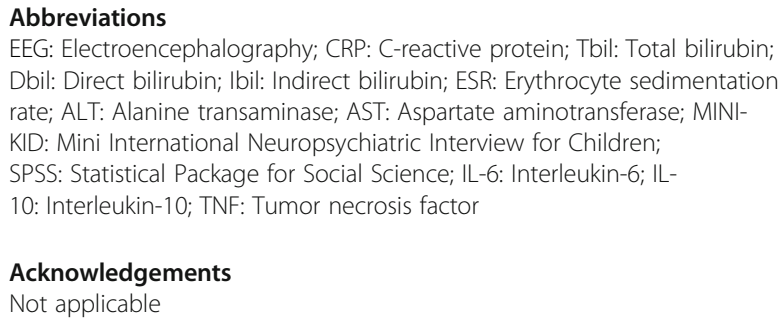

H. E.: study design, literature search, data acquisition and analysis, manuscript preparation and editing. W. E.: study design and manuscript review. M. M.: study design, literature review, statistical analysis, and manuscript review. The authors read and approved the final manuscript.

\section{Funding}

This work has not received any governmental or non-governmental funds.

Availability of data and materials

The datasets used and analyzed during the current study are available from the corresponding author on reasonable request.

\section{Ethics approval and consent to participate}

The study was performed in accordance with the Declaration of Helsinki and approved by the ethical committee of Menoufia Faculty of Medicine in December 2015.

Written informed consent was obtained from parents, and informed assent was obtained from the children before the collection of data. Data and headache diaries for patients were obtained from the patients or their parents

\section{Consent for publication}

Not applicable

\section{Competing interests}

The authors declare that they have no competing interests.

Received: 7 January 2020 Accepted: 24 July 2020

Published online: 06 August 2020

\section{References}

1. Chu ML, Shinnar S. Headaches in children younger than 7 years of age. Arch Neurol. 1992:49:79-82.

2. Oakley CB, Kossoff EH. Migraine and epilepsy in the pediatric population. Curr Pain Headache Rep. 2014;18:402.

3. Gelfand AA. Migraine and childhood periodic syndromes in children and adolescents. Curr Opin Neurol. 2013;26:262-8.

4. Guidetti V, Galli FT, Fabrizi P. Headache and psychiatric co-morbidity: clinical aspects and outcomes in an 8-year follow-up study. Cephalgia. 1998;18:455-62.

5. Egger $\mathrm{H}$, Angold A, Costello EJ. Headaches and psychopathology in children and adolescents. J Am Acad Child Adolesc Psychiatry. 1998;37:951-8.

6. Francesco P, Carlo F. Ictal and interictal EEG findings in children with migraine. J Headache Pain. 2004;5:23-9.

7. Cutrer. Pathophysiology of migraine. Semin Neurol. 2010;30(2):20-30.

8. Eising E, Datson NA, Maagdenberg AM, Ferrari MD. Epigenetic mechanisms in migraine: a promising avenue? BMC Med. 2013;11:26.

9. Lippi G, Mattiuzzi C, Cervellin G. C-reactive protein and migraine. Facts or speculations? Clin Chem Lab Med. 2014:52:1265-72.

10. Melake M, El-Sheikh W, El-shony H. Serum bilirubin as a neuroinflammatory biomarker in chilhood and adolescent migraine. J Neurol Sci. 2019; 405(Suppl):49 
11. Headache Classification Committee of the International Headache Society (IHS). The International Classification of Headache Disorders, 3rd ed (beta version). Cephalalgia. 2013;33:629-808.

12. Tarantino S, Capuano A, Torriero R, Citti M, Vollono C, Gentile S, et al. Migraine equivalents as part of migraine syndrome in childhood. Pediatr Neurol. 2014;3:1-5

13. Wang F, Van Den Eeden SK, Ackerson L, Salk SE, Reince RH, Elin RJ. Oral magnesium oxide prophylaxis of frequent migrainous headache in children: a randomized double- blind placebo controlled trial. Headache. 2003;43(6): 601-10.

14. Sheehan D, Janavs J, Baker R K, Harnett-Sheehan K, Knapp E, Sheehan M. Mini international neuropsychiatric interview, English version. 2006 , 5.0.0, DSM- IV.

15. Cuvellier JC, Lépine A. Childhood periodic syndromes. Pediatr Neurol. 2010; 42:1-11.

16. Peng $Y F$, Xie $L Q$, Xiang $Y, X u$ G. Serum bilirubin and their association with $C$ reactive protein in patients with migraine. J Clin Lab Anal. 2016;30(6):982-5.

17. Cao L, Xue L, Luo DM. Lower serum bilirubin concentration in patients with migraine. Int J Clin Exp Med. 2015;8(8):13398-402.

18. Wang F, He Q, Ren Z, Li F, Chen W, Lin X, et al. Association of serum levels of intercellular adhesion molecule-1 and interleukin-6 with migraine. Neurol Sci. 2015:36:535-40.

19. Liu R, Ma M, Cui M, Dong Z, Wang X, Zhang W, et al. Effects of tumor necrosis factor- $\beta$ (TNF- $\beta$ ) 252A>G polymorphism on the development of migraine: a meta-analysis. PLoS One. 2014;9:e100189.

20. Ohnaka K, Kono S. Bilirubin, cardiovascular diseases and cancer: epidemiological perspectives. Expert Rev Endocrinol Metab. 2010;5:891-904.

\section{Publisher's Note}

Springer Nature remains neutral with regard to jurisdictional claims in published maps and institutional affiliations.

\section{Submit your manuscript to a SpringerOpen ${ }^{\circ}$ journal and benefit from:}

- Convenient online submission

- Rigorous peer review

- Open access: articles freely available online

High visibility within the field

- Retaining the copyright to your article

Submit your next manuscript at $\boldsymbol{\nabla}$ springeropen.com 